\title{
Maria Aparecida Baccega: a palavra e 0 ato
}

\section{Maria Aparecida Baccega: the word and the act}

Adilson Odair Citelli ${ }^{1}$

Resumo: Este artigo tem o propósito de apresentar aspectos da trajetória pessoal, acadêmica, profissional de Maria Aparecida Baccega. Busca-se indicar algumas linhas de força que compuseram o quadro teórico e de influências no interior do qual a docente efetivou as suas investigações e escreveu significativo número de obras. Destaca-se neste conjunto reflexivo a presença de certa tradição teórica advinda do marxismo e como ele aparece desdobrado em temas que alcançam os estudos de linguagem, a análise discursiva, os vínculos ficção-história, as incursões no terreno da comunicação, da comunicação e educação, da telenovela, do consumo. Conclui-se evidenciando o caráter inovador levado a termo pelo trabalho da professora no campo da pesquisa e do magistério.

Palavras-chave: Maria Aparecida Baccega; comunicação; educação; telenovela; consumo.

Abstract: This article aims to present aspects of the personal, academic and professional trajectory of the Maria Aparecida Baccega. It seeks to indicate some lines of strength that made up the theoretical framework and influences within which the professor carried out her investigations and wrote a significant number of works. In this reflective set, the presence of a certain theoretical tradition arising from marxism and how it appears unfolded in themes that reach language studies, discursive analysis, fiction-history links, incursions in the field of communication, communication and education stands out, soap opera and consumption. It concludes by highlighting the innovative character carried out by the professor's work in the field of research and teaching.

Keywords: Maria Aparecida Baccega; communication; education; soap opera; consumption.

1 Universidade de São Paulo (USP). São Paulo, SP, Brasil.

https://orcid.org/0000-0002-0838-9917. E-mail: citelli@uol.com.br. 
Preso à minha classe e a algumas roupas, vou de branco pela rua cinzenta (...)

Carlos Drummond de Andrade

\section{Achegas}

As expansões retóricas não se esquivam a determinadas artimanhas: podem esconder o que não deve ser dito, revelar a negativa, prometer o impossível, justificar a inação. Talvez um dos primeiros desafios de quem se empenha no mundo da linguagem seja, exatamente, encontrar o seu lugar dentro dele e, ao menos, tentar entendê-lo, acertando os termos nos quais o jogo será jogado. É possível que deste enorme desafio resulte a força motriz animadora das andanças ético-morais, políticas, ideológicas, valorativas, para avocar alguns termos cuja fusão amarra os vínculos entre dizer e fazer. Tudo indica residir, aqui, a vitalidade de onde derivará toda sorte de inflexões éticas, morais, políticas, valorativas, que facultam os vínculos palavras-atos. Ajustar os dois atributos, na fusão signo e sentido, linguagem e princípios, implica encontrar durante a travessia o substantivo coerência, algo que pede requisita porfia renhida e de custos, muitas vezes, elevado. Perseguir a congruência não significa, porém, mergulhar no território da inflexibilidade e da ortodoxia que ignora a diferença, haja vista inexistir, como ponto de partida, contradição entre ideias em circulação e reconhecimento de perspectivas distintas. A determinado senhor, com o qual ela compartilharia alegremente o banquete celeste - caso acreditasse em plagas tão etéreas -, é atribuída frase assegurando estarem firmeza e ternura incluídas no mesmo pacote: "hay que endurecerse, pero sin perder la ternura jamás".

Como estou falando de Maria Aparecida Baccega pareceu pertinente iniciar pelo ponto que, de um ou outro modo, exerceu papel decisivo em seu projeto intelectual, de pesquisadora e docente, na vida cotidiana, nos engajamentos políticos, nos afetos: a linguagem e seus arranjos; o ajuste fino entre enunciados verbais e inserção social; a responsabilidade de quem diz sobre o que é dito. Ela gostava de lembrar que as 
palavras não se resumem a uma dimensão semântica, haja vista carrearem estratégias de ação e modos de os sujeitos se revelarem no mundo. Difícil pensar aquela mulher alta, de pele e olhos claros, gestos largos, certa impaciência e voz firme "como boa filha de italiano que sou", em cenário do qual se afastem os desafios da linguagem.

\section{Interregno político-sentimental}

Conheci a que viria a ser uma amiga por quase meio século, no tumultuário dos anos 1970. Talvez fosse o final de fevereiro, o que não deixa de ser uma coincidência com o nosso último encontro, também ocorrido naquele mês, agora em 2020, com ela já combalida em leito hospitalar.

Em decorrência do AI-5, a ditadura militar havia recrudescido a sanha de violência e levando às prisões milhares de brasileiros e brasileiras, dentre outros o companheiro da Baccega, José Adolfo de Granville Ponce, jornalista de publicações que fizeram época, como a revista Realidade e futuramente editor de casas publicadoras, a exemplo da Editora Ática, na qual dirigiu a importante coleção de livros universitários Ensaios. Igualmente encarcerado e amigo do expansivo Granville, por sua vez visitado semanalmente pela senhora de presença forte, carregada de mantimentos que iam para o marido, mas sempre com quantidade maior e a ser distribuída para os outros prisioneiros políticos, passei a me relacionar com ela. Admirava a generosidade e o destemor da mulher do Granville, que não raro ajudava outras famílias de presos, no que havia de possibilidades materiais - a peça de roupa faltante, os óculos a serem consertados, o remédio indispensável, a carta colocada no correio -, os aconselhamentos de várias ordens, a solidariedade ativa - sobretudo com os mais indefesos, muitas vezes sem parentes em São Paulo, com problemas para obter algum auxílio jurídico. E mesmo a execução de tarefas cujo risco se fazia evidente, como estabelecer contato com organizações políticas clandestinas e mesmo abrigar pessoas sob mira da repressão política. Na miudeza de alguns procedimentos é possível vislumbrar a configuração do caráter e da personalidade da Baccega. 
Ao correr do tempo ficamos mais próximos e conversa aqui e ali, identificamos interesses comuns, que iam além da política, e encontravam os terrenos da literatura, da linguagem, dos desafios da educação, dos descaminhos de um país que parecia fadado a viver um longo inverno de obscurantismo, regressão, intolerância, traços dos quais ainda não nos afastamos e sempre prontos a emergir com a natural brutalidade de seus arroubos.

A filha de imigrante italiano, das classes proletárias de Ribeirão Preto, preparada para o casamento, criação de filhos, trabalhos domésticos, trazia desde cedo o elemento da insurgência, do olhar desconfiado para o pacato ritual da submissão e acomodação aos valores da sociedade patriarcal interiorana. Como costumávamos brincar, deu tudo errado, ou, na tradução popular, ninguém havia pactuado com os russos. E a desordem que não brinca em serviço saiu a passos largos: ingresso no Partido Comunista, o primeiro casamento desfeito, filho pequeno para criar, estudo e trabalho duro para sobreviver, mundo a ser alcançado: o pachorrento quadrado interiorano havia ficado pequeno e o bacharelado concluído em Direito não teria força suficiente para segurar a moça voluntariosa num escritório dedicado a acalmar as aflitas almas dos e das litigantes à busca do acerto de contas com o código penal, trabalhista, civil, da família e quejandos concernentes às lides jurídicas. A mudança para São Paulo, mais do que o transporte de bugigangas domésticas, implicava realizar um projeto de vida em busca de maior liberdade de ação e procedimentos pessoais, novas experiências de trabalho e desafios intelectuais, a exemplo do mestrado não concluído na veneranda São Francisco, a nova graduação em Letras na Universidade de São Paulo e daí a longa, exitosa e consabida carreira universitária.

Cessadas as tais conversas, fomos nos rever poucos anos depois, à volta de 1974. O local do encontro foi uma festa que procurava reunir forças e fundos para municiar a luta pela volta da democracia, naquele momento sendo retomada e alongada até as campanhas das diretas já, em 1984, e o fim da ditadura com a edição da Carta Constitucional de 1988 - aquela chamada de cidadã pelo então deputado Ulysses 
Guimarães e agora, também ela, vilipendiada e alvo de todo candidato a Simão Bacamarte do século XXI, com os seus esdrúxulos pedidos de intervenção militar e fim do Supremo Tribunal Federal, do Congresso Nacional, da razão, da ciência, da arte, da educação pública de qualidade, enfim, de tudo o que sugira inteligência e civilidade. Imagino quais seriam as reações da minha amiga, caso estivesse viva e com a plena saúde de tempos idos.

O aludido reencontro ocorreu, aliás, tocado pelos sons da alegria e pelos ares do espanto: eis que ouço um grito tonitruante acompanhado do sorriso efusivo e a mulher alta vindo em minha direção acompanhada entre os dedos por um orgulhoso cigarro de palha. E se tratava de fumo de corda, algo hoje meio impensável, mormente entre as moças e moços da classe média urbana, a menos que se esteja a considerar alguma variação da diamba - algo na qual a nossa pantera jamais toparia dar sequer um tabefe.

No andamento, estreitamos vínculos que se espalharam por inúmeras iniciativas profissionais e que convergiram para um período de quase 20 anos nos quais estivemos juntos como professores da Escola de Comunicações e Artes da Universidade de São Paulo. Após a aposentadoria e tendo iniciado nova fase de trabalho na Escola Superior de Propaganda e Marketing, Baccega ajudou a organizar os primeiros momentos do curso de pós-graduação em Comunicação e Práticas de Consumo, do qual foi coordenadora adjunta entre 2003 e 2007. A despeito dos diferentes locais de trabalho, continuamos em íntima colaboração intelectual e convivência afetiva até que viesse a falecer. Tive outras oportunidades para tratar de aspectos da vida da Baccega, em artigos e exposições, assim como já é possível ler trabalhos de autores que sistematizaram a biografia dela. Todo este material pode ser encontrado nas bases de dados. De sorte que vou me ater a pontos sobre os quais pouco avancei nas iniciativas anteriores e que talvez colaborem para uma compreensão mais ampla do itinerário político, intelectual, profissional da nossa companheira. 
Antes, porém, cabe um adendo, destacado para lamentar práticas que nada engrandecem a vida universitária e que exemplificam a existência de custos individuais quando se procura levar a termo os citados nexos entre dizer e fazer.

A intelectual inquieta e marcada por tantas iniciativas conheceu percalços e obstáculos - como costuma ocorrer com os sujeitos que não aceitam as coisas segundo a ordem das imposições delas, tampouco concebem firmar pactos em torno de projetos pessoais entregues à solidão de seus exclusivos interesses, menos ainda admitem tergiversar sobre procedimentos éticos. De um lado, as posições fortes temperadas no calor das várias dimensões da luta política e das quais a nossa professora nunca se eximiu. De outro, as tensões do poder, que no caso específico da arena universitária incluem não apenas as disputas simbólicas, mas também os espaços físicos, os cargos, os lugares hierárquicos. Aqui, a nossa professora conheceu oposições mais ou menos explícitas que cobraram alto preço: demissão em instituição particular por defesa de princípios inegociáveis; descontinuidade, na instituição pública, de uma jornada que, malgrado ser totalmente exitosa no terreno intelectual, na pesquisa, na produção, no envolvimento profissional, não chegou aonde, por força da competência, deveria ter chegado. Em uma carreira que tem como último nível o cargo de Professor Titular, Maria Aparecida Baccega aposentou-se na Escola de Comunicações e Artes, em 2003, no penúltimo degrau, como Professora Associada. Os motivos, certamente, nada disseram respeito à tão decantada meritocracia.

\section{Inquietação produtiva}

Chega mais perto e contempla as palavras.

Cada uma tem mil faces secretas sob a face neutra e te pergunta, sem interesse pela resposta, pobre ou terrivel, que lhe deres: Trouxeste a chave? Carlos Drummond de Andrade 
Haja vista o caráter plural das pesquisas e das obras escritas por Maria Aparecida Baccega é necessário apelar para o espírito de síntese, necessariamente precário e um tanto insatisfatório, mesmo porque há limites editoriais para este artigo. Assim, cavoucados os redutores isotópicos, é possível encontrar uns liames que, segundo o meu entendimento, dão coerência ao projeto intelectual por ela buscado ao longo da sua caminhada acadêmica. E o que nele se encontra é o movimento teórico-prático dialeticamente orientado segundo a perspectiva marxista - o exame das fontes bibliográficas, das preocupações temáticas e formas de abordá-las, apenas esclarece a assertiva geral. E foge ao acaso o fato de o termo práxis (e seus derivados) ganhar permanente convocação nos discursos elaborados pela nossa professora. Trata-se de uma maneira através da qual o debate envolvendo os assuntos em análise (derivados de pesquisa, da metacrítica, das várias ponderações) seguir determinado roteiro para o qual convergem o cenário histórico, os fatores socioeconômicos, as ideologias, a cultura e o desejo de promover algum tipo de intervenção - ou destinação - do que está passando pelo crivo reflexivo. O que não deixa de ser uma estratégia de militância e combate no campo intelectual, dos conceitos e das ideias. É um modo de firmar posição, esclarecer o lugar a partir do qual o mundo é visto e pensado. A se observar que utilizo o substantivo militância em direção muito precisa, que não sendo necessariamente partidária, revela o foco de visão, os compromissos abrangidos, os interesses em jogo, os eventuais rumos a serem trilhados.

Penso ser arriscado retirar a pesquisa e a produção acadêmica da Baccega destas circunstâncias, manietando propósitos e fragilizando envolvimentos. Esclareçamos até porque, certamente, ela gostaria disto. Aqui, não se fala de engajamentos com grupos políticos organizados, que os teve até certa altura dos anos 1980, senão de uma inflexão dialética, como já nos referimos, a contemplar no seu miolo epistêmico a ideia da práxis. Digamos que a vivência orgânica, como fora o vínculo dela com o PCB e indiretamente com a ALN (Aliança Libertadora Nacional), ganhou residual a ser mantido em chave quase afetiva. $\mathrm{O}$ 
que salientamos, portanto, em expressões como metodologia dialética, ativação da práxis, entendimento militante, diz respeito a uma atitude frente ao mister intelectual compreendido como determinação científica, seriedade na pesquisa, acumulação de competências, estratégia de esclarecimento qualificado das coisas do mundo e vetor de possível transformação social. Nem teoria ou metacrítica como ocorrências autônomas pertencentes a esferas próprias com pouco ou nenhum nexo com o "mundo da vida", nem associação voluntarista ou populista de procedimentos investigativos ou imediatismos localizados nos embates de circunstância. Pudesse falar na existência de um método a garantir recorrência interna aos trabalhos levados a termo pela nossa professora, diria que está ele posto nas linhas gerais acima esboçadas.

O desdobramento de tal método encontra temas e formas que circulam, prioritariamente, por quatro grandes eixos interconectados: linguagem/língua/análise discursiva; história e (tele) ficção; comunicação e educação; consumo. Acompanhando este roteiro - algo perscrutável através dos títulos das pesquisas, livros, artigos, palestras, cursos proferidos, registrados no currículo Lattes - encontraremos nas citadas linhas de força o grosso da sua produção.

Em obras como Estudos de comunicação e análise do discurso: teoria e prática; Comunicação e Linguagem: discursos e ciência; Lenguaje verbal y médios de comunicación; ou mesmo Palavra e discursos: história e literatura, o que vemos é o chamamento linguageiro para orientar e sobre o qual refletir em diferentes desdobramentos. O lugar especial ocupado pelo universo das palavras ilumina os outros três eixos na sequência acima. E mesmo quando trabalhando de modo mais próximo aos signos icônicos, às imagens televisivas, o pé de apoio não deixava o chão abrigador do verbum. Tal entendimento derivava de convicções e influências advindas de, ao menos, duas fontes: Adam Schaff e Mikhail Bakhtin - houvesse espaço para tanto seria preciso abrir parêntese para esclarecer como os dois autores são acionados, cruzados e relacionados a outras fontes de igual ou próxima linhagem teórica; o assunto será 
brevemente retomado abaixo, entretanto as suas implicações ficam para eventual outra oportunidade.

Da mesma forma, é possível reconhecer o lugar que a interdisciplinaridade ocupará no pensamento da Baccega. No primeiro e terceiro livros acima, o material discursivo verbal é posto em diálogo com os estudos comunicacionais; no segundo, os mesmos vínculos rumam para o discurso científico; no último trata-se da variável literária em que se examina a partir do romance Mayombe, escrito pelo angolano Pepetela (Artur Carlos Maurício Pestana dos Santos), e voltado a narrar os embates dos guerrilheiros angolanos contra os militares colonialistas portugueses. Assunto este, ademais, ao gosto da professora por associar ao tema da libertação nacional os circuitos palavra-história-ficção.

O esclarecimento do projeto elaborado em torno das referidas quatro linhas de força, pode ser identificado em outras obras - e aqui estou me limitando, por razões evidentes, apenas aos livros por ela escritos individualmente ou em colaboração. Avocadas as inter-relações - termo que a seguia, presumo, até quando dormia - televisão/teleficção e consumo seguem títulos como: Telenovela nas relações comunicação e consumo: diálogos Brasil e Portugal (em colaboração com Márcia Tondato); Consumindo e vivendo a vida: telenovela e consumo e seus discursos (em colaboração com Isabel Orofino). No tangente aos nexos comunicação e educação dedicarei espaço maior em seguida, fazendo menção, por ora, a dois títulos: Televisão e Escola: uma mediação possivel?; Contar histórias, tecer culturas: as intersecções entre comunicação, educação e consumo na teleficção brasileira.

Em resumo, existe material a sobejo (e aqui sequer nos aventuramos nos seus artigos, palestras, cursos) para justificar a existência das consignadas quatro grandes linhas de força a alimentarem o legado de Maria Aparecida Baccega, arranjados sob a luz dos dois vetores integrados e para os quais demos destaque: linguagem e interdisciplinaridade.

No primeiro caso, em tradução nos estudos concernentes à analise discursiva (de linha francesa, como gostava de acentuar, em companhia de Pêcheux, Fuchs, Courtine, Orlandi etc., à qual foi incorporada o 
russo Bakhtin) - matéria a que se dedicava com afinco; no segundo, como procedimento inescapável para quem desejasse avançar pelo terreno dos estudos comunicacionais e da linguagem. Para ela, a Comunicação tem os seus objetivos, constituindo-se em área de saber com método, estratégia de pesquisa, inserção no debate social, propósitos pragmáticos, pelo que estrutura um campo de conhecimento. Dentro deste arcabouço desenvolve-se o diálogo com as diferentes áreas, âmbitos científicos, sem os quais a Comunicação restaria canhestra. E reiterava que ao acionar a filosofia, a sociologia, a teoria da linguagem, a Comunicação não poderia reduzir-se a nenhuma delas, senão incorporá-las dando solidez ao próprio sentido ensejado no substantivo campo. Está espalhada na obra da Baccega esta ideia-chave de que "o lugar de fazer teoria filosófica, sociológica, linguística é nas suas instituições de origem, na Escola de Comunicação é preciso promover intenso diálogo com tais áreas, não para a elas subsumir-se, mas com o propósito de dar consistência ao nosso próprio campo; o embate com as outras áreas não deve ocorrer na porta de entrada, mas sim na porta de saída”. As aspas são, evidentemente, aproximativas.

\section{Ação educadora}

Um galo sozinho não tece a manhã: ele precisará sempre de outros galos. De um que apanhe esse grito que ele e o lance a outro: de um outro galo que apanhe o grito que um galo antes e o lance a outro; e de outros galos que com muitos outros galos se cruzam os fios de sol de seus gritos de galo para que a manhã, desde uma tela tênue, se vá tecendo, entre todos os galos.

João Cabral de Melo Neto 
O termo educação será aqui utilizado em sentido amplo, envolvendo não apenas o plano formal, mas, igualmente, os procedimentos de sujeitos que estando no mundo desejam mudá-lo através de atitudes e palavras cujo espraiamento promove o conhecimento, a informação, o espírito analítico-crítico, alcançando certo número de interlocutores.

Nesta abrangência, Maria Aparecida Baccega foi educadora em tempo integral.

Testemunhei, haja vista dividirmos por vários anos a mesma sala de trabalho na ECA-USP, os esforços por ela realizados no sentido de prover os cursos que ministrava de propostas convergentes às novas concepções de estudos de linguagem, da comunicação, da educação, da cultura.

Daí a sociolinguística, cuja apreensão vem da obra de Marcel Cohen, Tullio De Mauro, Michael A.K. Halliday, William Labov, Robert Lado e Dino Preti - de quem foi assistente na ECA até assumir em definitivo a cadeira de Comunicação Linguística, que ambos dividiam até o retorno daquele professor ao seu posto na FFLCH-USP. Tal perspectiva acerca dos estudos de linguagem era, pelos inícios dos anos 1980, ainda novidade entre nós. Ou ainda, os problemas envolvidos no conceito de edição dos textos disponibilizados através dos media - e uma frase que lhe era recorrente: "O que lemos no jornal e vemos na televisão é o mundo editado”. E mais, os temas da recepção e das mediações, para os quais buscava fundamentação em Raymond Williams, David Harvey, Richard Hoggart, Stuart Hall, Jesús Martín-Barbero.

Podemos prosseguir, conquanto em chave de sistematização, mencionando o esforço que a nossa professora fazia objetivando a proporcionar aos seus alunos vivência mais forte com os desafios comunicacionais, das interfaces comunicativo-educativas, da cultura, da política; era comum que em aula dirigida, por exemplo, a tópicos da semântica adviesse questão referente aos modos de fala da classe operária ou dos trabalhadores rurais e, com isto, textos de caráter geral incluindo Paulo Freire, Marx, Ecléa Bosi, em esforço para mostrar como os fenômenos da linguagem dizem respeito a contextos, histórias, segmentos etários e sociais, lugares econômicos etc. Entendia ela que para formar um bom comunicador 
era imperioso trazer à luz este caráter complexo da linguagem, necessariamente, articulado com o mundo, algo que não se esgotava, portanto, no ensino das técnicas de produção e circulação dos discursos.

O espírito de inovação ganhava materialidade nas propostas formuladas aos alunos e alunas visando a que realizassem pesquisas de campo - eco da sociolinguística - sobre níveis e variabilidades de falas utilizadas pela população e os confrontos com os registros processados através dos meios de comunicação. As enquetes, que conheciam meses de trabalhos preliminares, faziam a turma ir às ruas, entrevistar pessoas e não apenas conhecer os seus idioletos, mas, também, identificar, neles, valores e ideologias; tal contato físico deveria representar para os/as estudantes mais do que o cumprimento da tarefa escolar, senão permitir fosse ativada reflexão acerca dos processos de alteridade.

Na pós-graduação, Baccega dedicou-se a uma de suas várias faces do fazer acadêmico, referente à pesquisa dos assuntos emergentes, como as telenovelas, ainda ao tempo, consideradas produtos menores gestados pela maquinaria alienante da indústria cultural. Ficou conhecida a entrevista dada por ela, em 1996, às páginas amarelas da revista Veja, em que defendia fosse aquele gênero teleficcional estudado na universidade, haja vista ser ele veículo de ideologias, comportamentos, estética, moda, manifestações políticas etc. E deixou a frase provocadora de polêmica ao considerar a telenovela "o grande produto cultural brasileiro". A assertiva, hoje aclimatada, recebeu, naquele momento, críticas de diversos quadrantes, as quais soube pacientemente - o que sequer correspondia muito à sua maneira de ser - esgrimir e tocar a vida em frente, tornando-se, inclusive, uma das primeiras coordenadoras do Núcleo de Pesquisa de Telenovela do CCA/ECA/USP.

No capítulo das ousadias, a docente, pesquisadora e gestora fundiram-se para criar, em 1994, junto com outros colegas do Departamento de Comunicações e Artes, da ECA/USP, a revista Comunicação ๒ Educação. Desnecessário reiterar o sucesso do empreendimento, cujos frutos, passados 26 anos, continuam a ser colhidos na herança de um dos mais importantes periódicos ainda em circulação no Brasil 
e reconhecido internacionalmente pela temática que leva a termo. Em boa hora e até como reconhecimento do trabalho realizado no eixo das inter-relações comunicação/educação/consumo, a Escola Superior de Propaganda e Marketing/SP, onde atuou como professora da pós-graduação a partir de 2003, em parceria com o Instituto Palavra Aberta, criou a cátedra Maria Aparecida Baccega.

É preciso aduzir, last but not least, nesta trilha da educadora em tempo integral que foram mais de 50 anos de lida, a começar pela alfabetizadora que atuou em escolas rurais em Ribeirão Preto, passando pelos programas de Madureza, como os do tradicional Santa Inês, pela direção e coordenadoria de escolas do SESI, até fixar-se no magistério superior. Nesta faina andou pela Ribeirão natal, Brasília, Osasco, São Paulo. Ajudou a divulgar o método Paulo Freire, o pensamento de Darcy Ribeiro, para ficarmos com dois nomes paradigmáticos na educação brasileira. E na companhia daqueles dois mestres, juntamente com as convicções forjadas na luta política por uma sociedade mais justa e solidária, defendeu, com ardor, o ensino público universalizado e de qualidade.

É compreensível que tenha ela se tornado uma respeitada docente, com reconhecimento de alunos, alunas e colegas envolvidos nas questões comunicativo/educativas.

\section{Enfim}

Tendo com ela privado de tão extensa jornada de trabalho, de pesquisa, de lutas comuns, de eventuais discordâncias, de alguns desentendimentos, observei, sobretudo, a presença de admirável itinerário político-acadêmico, a enorme capacidade de doação ao bem comum, a forma generosa de acolher os mais humildes, a coerência de princípios, a incapacidade de fazer da máscara uma forma de relacionamento social. Maria Aparecida Baccega, como todos nós, apresenta as suas fragilidades, limites e dificuldades, mas dela podemos afastar a ideia ilusória, tão em voga nos dias correntes, segundo a qual é possível ao sujeito viver como se fosse uma ilha. 
Ao fechar este texto, o sentimento é o de que a personagem não foi capturada em sua complexidade, seja por deficiências do amigo escriba, seja pelos limites editoriais existentes. Ademais, como restringir em poucas páginas - sem cair no encomiástico e laudatório, a que nem eu me atreveria, tampouco ela aceitaria - tantos anos de trabalho, amizade, confidências e lutas comuns. Apenas me ocorreu deixar o poema escrito por um anônimo (mas, atribuído ao uruguaio Mario Benedetti), que ela leria a plenos pulmões se entre nós estivesse, para dizer acerca da trágica quadra histórica pela qual passamos, sobretudo, em país como o nosso bafejado pelos ares da regressão, do autoritarismo, do ressentimento:

No te rinda

No te rindas, aún estás a tiempo

De alcanzar y comenzar de nuevo,

Aceptar tus sombras,

Enterrar tus miedos,

Liberar el lastre,

Retomar el vuelo.

No te rindas que la vida es eso,

Continuar el viaje,

Perseguir tus sueños,

Destrabar el tiempo,

Correr los escombros,

Y destapar el cielo.

No te rindas, por favor no cedas,

Aunque el frío queme,

Aunque el miedo muerda,

Aunque el sol se esconda,

$Y$ se calle el viento,

Aún hay fuego en tu alma

Aún hay vida en tus sueños.

Porque la vida es tuya y tuyo también el deseo

Porque lo has querido y porque te quiero

Porque existe el vino y el amor, es cierto.

Porque no hay heridas que no cure el tiempo.

Abrir las puertas,

Quitar los cerrojos, 
Abandonar las murallas que te protegieron,

Vivir la vida y aceptar el reto,

Recuperar la risa,

Ensayar un canto,

Bajar la guardia y extender las manos

Desplegar las alas

E intentar de nuevo,

Celebrar la vida y retomar los cielos.

No te rindas, por favor no cedas,

Aunque el frío queme,

Aunque el miedo muerda,

Aunque el sol se ponga y se calle el viento,

Aún hay fuego en tu alma,

Aún hay vida en tus sueños

Porque cada día es un comienzo nuevo,

Porque esta es la hora y el mejor momento.

Porque no estás solo, porque yo te quiero.

\section{Referências}

BACCEGA, M. A. Televisão e escola: uma mediação possível? São Paulo: SENAC, 2019a.

BACCEGA, M. A. Contar histórias, tecer culturas: as intersecções entre comunicação, educação e consumo na teleficção brasileira. 2019b (no prelo).

BACCEGA, M. A. Estudos de Comunicação e Análise do Discurso. São Paulo: Intermeios, 2014.

TONDATO, Márcia; BACCEGA, M. A. Telenovela nas relações comunicação e consumo: diálogos Brasil e Portugal. São Paulo: Paco Editorial, 2013.

BACCEGA, M. A.; OROFINO, M. I. (Org.) Consumindo e vivendo a vida: telenovela e consumo e seus discursos. São Paulo: Intermeios, 2012a.

BACCEGA, M. A. Comunicación y culturas del consumo. Espanha: Comunicación Sociales, Saracozza, 2012b.

BACCEGA, M. A. Comunicação/educação a construção de nova variável histórica. In: CITELLI, Adilson Odair; COSTA, Maria Cristina Castilho (Org.) Educomunicação: construindo uma nova área de conhecimento. São Paulo: Paulinas, 2011, p. 31-42.

CASTRO, G. S. ; BACCEGA, M. A. (Org.) Comunicação e consumo nas culturas locais e global. São Paulo: ESPM, 2009.

BACCEGA, M. A. Palavra e Discurso História e Literatura. São Paulo: Ática, 2003. 
BACCEGA, M. A. Comunicação e Linguagem: discursos e ciência. São Paulo: Editora Moderna, 1998.

BACCEGA, M. A. Palavra e discurso: história e literatura. São Paulo: Ática, 1995.

BACCEGA, Maria Aparecida. O movimento entre a ficção e a história: o caso Mayombe. Revista África, n.12-13, p. 137-148, 1990.

BACCEGA, Maria Aparecida. Lenguaje Verbal y Medios de Comunicacion. Havana: EICTV, 1988.

BACCEGA, M. A. O campo da comunicação/educação e as práticas de recepção: o papel das mediações. [s.e.] [s.d.]. Disponível em: http://www.compos.org.br/data/biblioteca_1283.pdf.

\section{Sobre 0 autor}

Adilson Odair Citelli - Possui graduação em Letras pela Universidade de São Paulo. Na mesma instituição realizou o mestrado e o doutorado, ambos na área de Literatura Brasileira. Professor Titular junto ao Departamento de Comunicações e Artes da ECA/USP. Pesquisador 1B do CNPq.

Data de submissão: 14/06/2020

Data de aceite: 16/07/2020 